\title{
A Chemo- and Regioselective Tandem [3+2]Heteroannulation Strategy for Carbazole Synthesis: Synergizing Two Mechanistically Distinct Bond-Forming Processes
}

\author{
Emma Campbell, a ${ }^{\ddagger}$ Andrea Taladriz-Sender, ${ }^{\ddagger}$ Olivia I. Paisley, ${ }^{\mathrm{a}}$ Alan R, Kennedy, Jacob T. Bush, ${ }^{\mathrm{b}}$ \\ Glenn A. Burley ${ }^{a^{*}}$
}

${ }^{a}$ Department of Pure Applied Chemistry, University of Strathclyde, Thomas Graham Building, 295 Cathedral Street, Glasgow, UK, G1 1XL.

${ }^{b}$ GlaxoSmithKline, Medicines Research Centre, Gunnels Wood Road, Stevenage, Hertfordshire, UK, SG1 2NY.

Supporting Information Placeholder

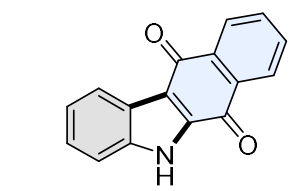

carbazole-1,4-quinones<smiles></smiles>
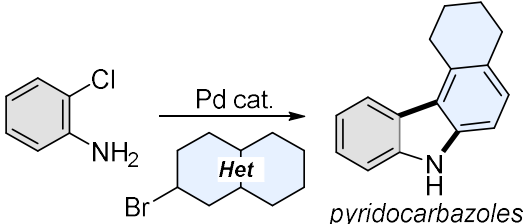

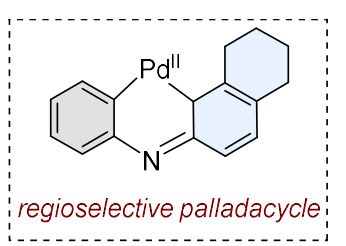

- Mechanism-directed optimization $\quad \bullet>20$ examples of tri-/tetracyclic carbazoles

ABSTRACT: A modular approach to prepare tri- and tetracyclic carbazoles by a sequential [3+2]heteroannulation is described. First, optimization of a Pd-catalyzed Buchwald-Hartwig amination followed by $\mathrm{C} / \mathrm{N}$-arylation in a one-pot process is established. Second, mechanistic analyses identified the origins of chemo- and regioselective sequential control of both bondforming steps. Finally, the substrate scope is demonstrated by the preparation of a range of tri- and tetracyclic carbazoles, including expedient access to several natural products and anti-cancer agents.

Carbazoles are ubiquitous $N$-heterocycles used throughout medicinal chemistry and the material sciences. ${ }^{1-3}$ From a pharmaceutical perspective, the carbazole core features extensively in drugs and natural products, many of which exhibit potent anti-proliferative activities (Figure 1a). ${ }^{4-9}$ The breadth of applications has inspired the development of numerous methodologies for their preparation.2, 9, 10 Pd-catalyzed processes in particular enable a [3+2]heteroannulation via a $\mathrm{Pd}(0)$-catalyzed Buchwald-Hartwig amination, ${ }^{11}$ followed by a $\mathrm{Pd}(\mathrm{II})$-catalyzed $C$-arylation at a late stage in a synthetic workflow. ${ }^{10-24}$ However, a generalized set of guidelines outlining the molecular determinants which define the chemo- and regioselective control of each $\mathrm{C}-\mathrm{N} / \mathrm{C}-\mathrm{C}$ bondforming reaction, and the factors which influence $\operatorname{Pd}(0)^{25}$ versus $\mathrm{Pd}(\mathrm{II})^{19}$ catalysis in a one-pot process has not been established. This is an important requirement for the formation of tetracyclic carbazoles where a regioselective $\mathrm{C}-\mathrm{H}$ activation step is required. ${ }^{2}$

In this manuscript, we establish reaction guidelines to prepare tri- and tetracyclic carbazoles by controlling the chemoselectivity of the first $\mathrm{Pd}(0)$-catalyzed $\mathrm{C}-\mathrm{N}$ bondforming step, and the regioselectivity of the second Pd(II)catalyzed $\mathrm{C} / \mathrm{N}$-arylation (Figure $1 \mathrm{~b}$ ). Our rationale was to use chloroanilines (1) to define the A-ring of a carbazole core, and heteroaryl bromides to form the C/D-rings of tricyclic and tetracyclic products. (a) Prominent bioactive carbazole-containing scaffolds.<smiles></smiles>

(b) This work: Pd-catalyzed tri-/tetracyclic carbazole synthesis

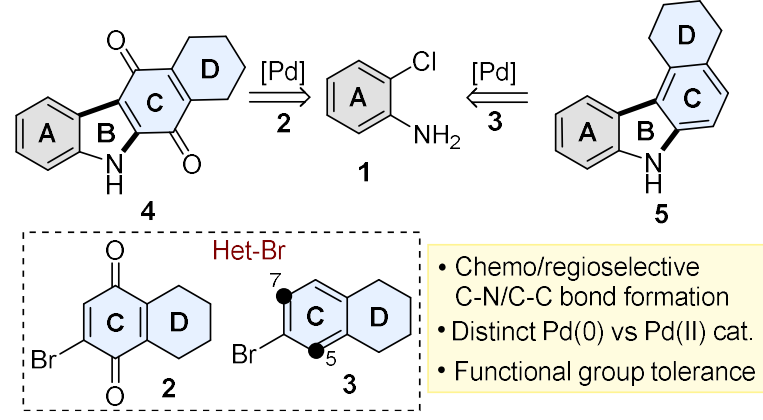

Figure 1. A generalized approach for the synthesis of tri-/tetracyclic carbazoles by Pd-catalyzed [3+2] heteroannulation.

For the synthesis of tetracyclic carbazoles, heteroaryl bromides (e.g., 3) have two competing $\mathrm{C}-\mathrm{H}$ activation sites. Alt- 
hough the 5-position of isoquinoline is the more nucleophilic site, ${ }^{27}$ the mechanistic determinants which control the regioselectivity of such a $\mathrm{Pd}(\mathrm{II})$-catalyzed $C$-arylation are not known. ${ }^{26,28-29}$

Our studies commenced with optimizing reaction conditions for the $\mathrm{Pd}(0)$-catalyzed $\mathrm{C}-\mathrm{N}$ bond-forming step using 4-methoxy-2-chloroaniline (1a) and 6-bromoisoquinoline (6a) as exemplar substrates (Scheme 1). An extensive screen (Table S1) identified DavePhos and $\mathrm{K}_{3} \mathrm{PO}_{4}$ as the optimal ligand/base pairing, which formed $\mathbf{7 a}$ in $87 \%$ yield.
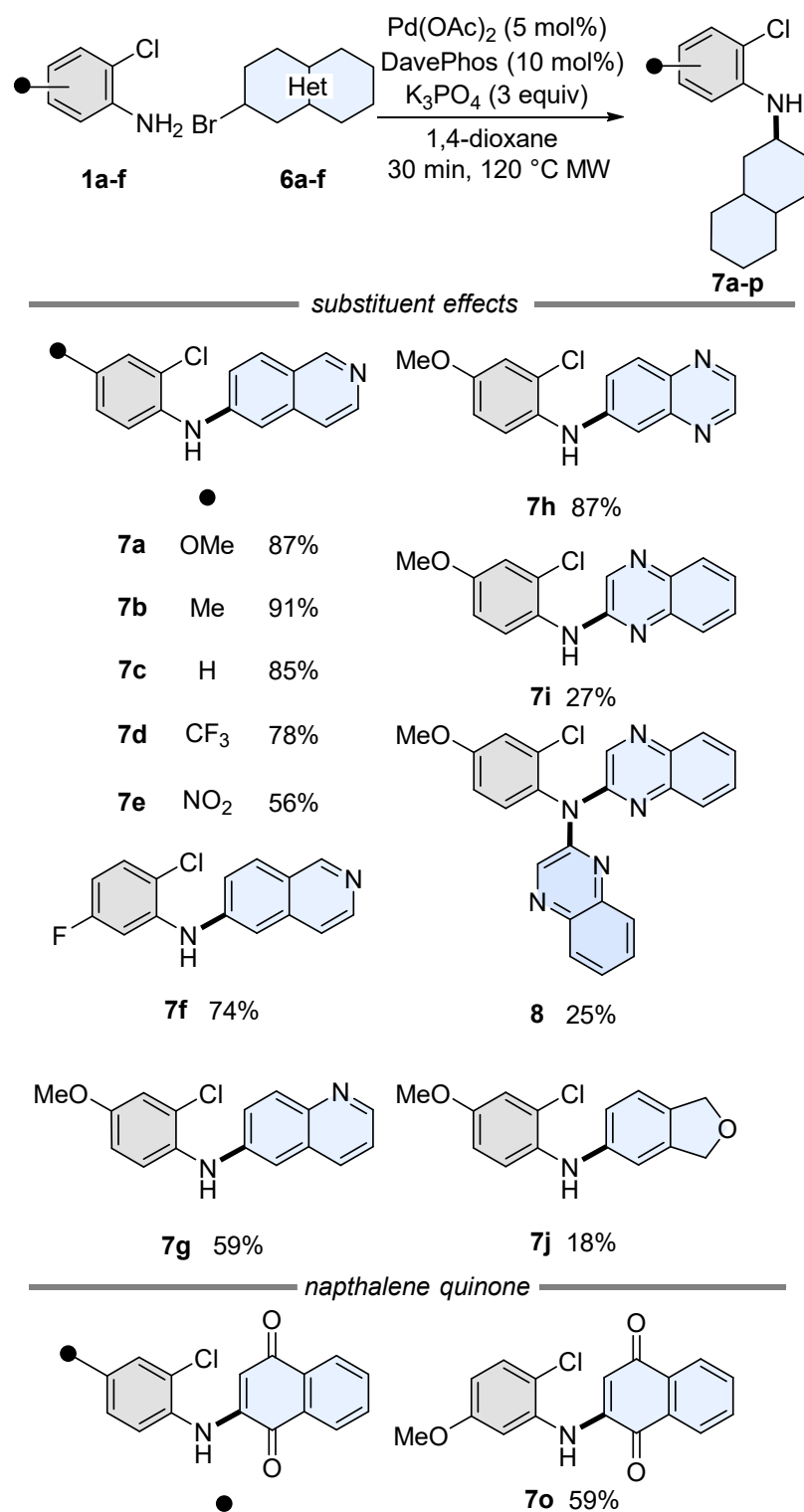<smiles>COc1ccc(Cl)c(NC2=CC(=O)c3ccccc3C2=O)c1</smiles>

$$
\begin{array}{ccc}
\text { 7k } & \text { OMe } & 81 \% \\
7 \mathbf{l} & \mathrm{Me} & 72 \% \\
7 \mathbf{m} & \mathrm{H} & 64 \% \\
7 n & \mathrm{CF}_{3} & 69 \%
\end{array}
$$

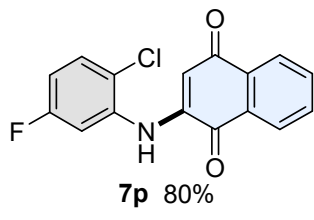

Scheme 1. Scope (isolated yields) of Buchwald-Hartwig amination.

Using these conditions secondary anilines $\mathbf{7 b - e ~ ( 5 6 - 9 1 \% ) ~}$ were obtained using chloroanilines ( $\mathbf{1 b}$-e) bearing electronrich and electron-withdrawing substituents when reacted with 6-isobromoquinoline (6a). The conditions tolerated a range of heteroaryl bromides to form $\mathbf{7 f - h}$, except for 2-bromoquinoxaline (6d). In this case, a mixture of secondary ( $7 \mathbf{i}$, $27 \%)$ and tertiary anilines $(8,25 \%)$ were formed. Using 5 bromo-1,3-dihydroisobenzofuran (6e) formed $\mathbf{7 j}$ in $18 \%$ isolated yield. This process was also compatible with 2-bromonapthalalene-1,4-dione (6f) producing 7k-p in 59-81\%.

With conditions for the $\mathrm{Pd}(0)$-catalyzed C-N bond-forming step established, the optimization of the one-pot process was explored (Table S2). ${ }^{1-6}$ The optimal ligand/base pairing of $\mathrm{HPCy}_{3} \mathrm{BF}_{4}$ with $\mathrm{K}_{3} \mathrm{PO}_{4}$ was identified, which formed 9a from $1 \mathbf{a}$ and $6 \mathbf{a}$ in $78 \%$ yield. This highlights that the second $\mathrm{C}-\mathrm{H}$ activation step is regioselective for the 7-position of $\mathbf{6 a}$. To further understand how the nature of the chloroaniline and heteroaryl bromide substrates influenced the chemoand regioselectivity of both bond-forming steps, a series of test reactions were undertaken (Scheme 2). Exchanging 6bromoisoquinoline (6a) for isoquinoline (10) formed dimethoxyphenazine (11) and the tertiary aniline (12) in $35 \%$ and $25 \%$ isolated yield, respectively (Scheme 2a). No dihydrophenazine was isolated from the reaction, which suggests an in situ oxidation occurred. ${ }^{34}$ No reaction occurred when isoquinoline (10) was the coupling partner with 1-chloro-3-methoxybenzene (13, Scheme 2b). Only secondary aniline (15) was isolated when para-anisidine (14) was reacted with 6-bromoisoquinoline (6a, Scheme 2c). Taken collectively, these test reactions highlighted the following requirements for the preparation of the tetracyclic core: (i) the aryl bromide is essential and prevents dimerization of the chloroaniline, (ii) whilst the absence of a bromo substituent in the heteroaryl substrate results in $\mathrm{C}-\mathrm{H}$ activation at the same site, there is little regiocontrol, (iii) a chloro substituent is essential for $C$-arylation.

The influence of the electron-donating aniline lone pair in the direct $C$-arylation step was then explored. We surmised that the acetylated substrate $(\mathbf{1 6})$ would deactivate the Cring and render the $C$-arylation less efficient. This indeed occurred as highlighted by the formation of deacetylated $C$ arylated regioisomers, $9 \mathbf{a}$ and $\mathbf{1 7}$, in 27\% total yield (1.2:1.0 9a:17). We assume that deacetylation occurs in situ because of the high temperatures and in the presence of base in the reaction mixture. An unexpected result was the formation of the linear tetracyclic carbazole 17, which arises from $\mathrm{C}-\mathrm{H}$ activation of the isoquinoline 7-position of 16. The formation of $\mathbf{1 7}$ suggests that $\mathrm{C}$-H activation of the 7-position is favored if the acetyl group is present prior to $C$-arylation. In contrast, if $\mathbf{7 a}$ is present - presumably formed by deactylation of 16 - $\mathrm{C}-\mathrm{H}$ activation at the 5-position occurs. We speculate that the acetyl group (i.e., 16) directs $\mathrm{C}-\mathrm{H}$ activation at this site via coordination of a Pd(II) species through the amide carbonyl. ${ }^{35,36}$

This series of reactions have guided us to propose that oxidative addition of the $\mathrm{C}-\mathrm{Cl}$ bond in 7a occurs first and proceeds via a $\operatorname{Pd}(0)$ species to form 18 (Scheme 2e). Pd(II)catalyzed $C$-arylation forms the palladacycle (19) followed by tautomerization (20). Finally, reductive elimination produces the $C$-arylated product (9a).

With mechanistic knowledge of the second $\mathrm{C}-\mathrm{C}$ bondforming step established, the substrate scope of the process was investigated (Scheme 3). 

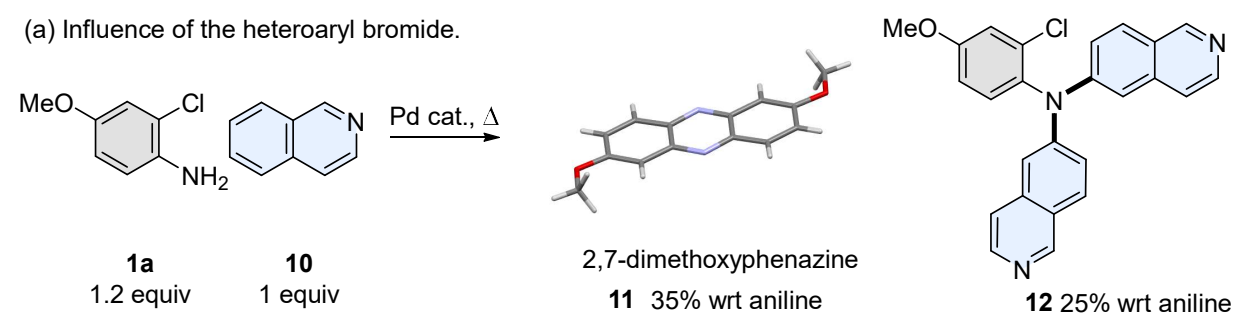

(b) Aniline is essential for C-N and C-C bond formation. $\quad$ (c) Aryl chloride essential for C-arylation.

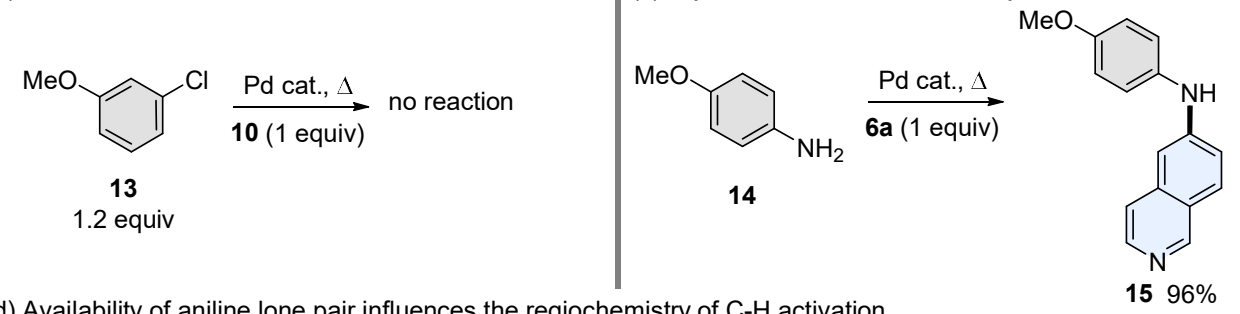

(d) Availability of aniline lone pair influences the regiochemistry of $\mathrm{C}-\mathrm{H}$ activation

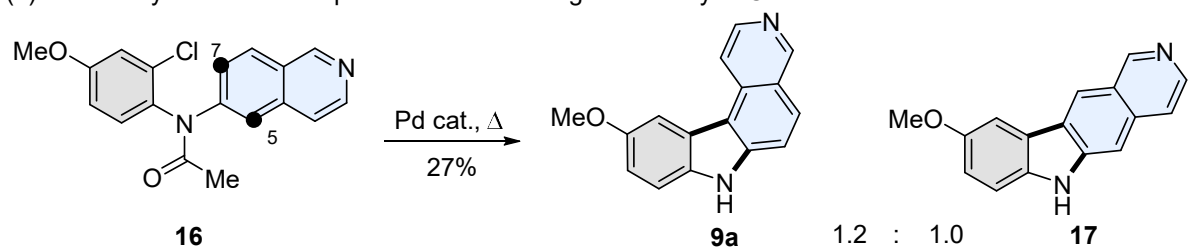

(e) Proposed intermdiates which define the regioselectivity of $C$-arylation.

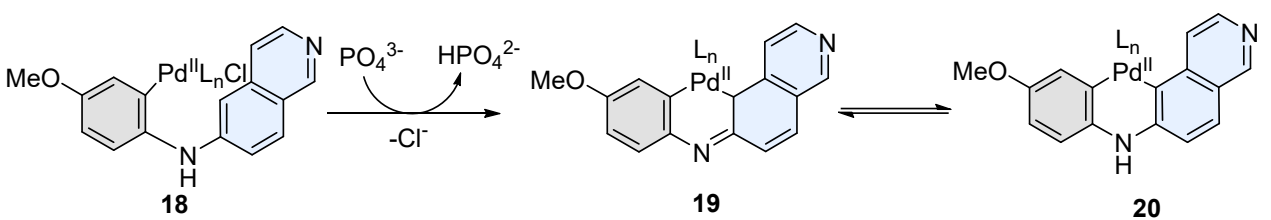

Scheme 2. Mechanistic studies of the [3+2] heteroannulation. Reaction conditions: $\mathrm{Pd}(\mathrm{OAc})_{2}(5 \mathrm{~mol} \%), \mathrm{HPCy}_{3} \mathrm{BF}_{4}$ (10 mol\%), $\mathrm{K}_{3} \mathrm{PO}_{4}$ (3 equiv), 1,4-dioxane (i) $30 \mathrm{~min}, 120^{\circ} \mathrm{C} \mathrm{MW}$; (ii) $8 \mathrm{~h}, 160{ }^{\circ} \mathrm{C} \mathrm{MW}$. wrt = with respect to.

The reaction conditions formed $7 H$-pyrido[3,4-c]carbazole analogues (9a-c). The presence of a nitro group resulted in only trace amounts of $9 \mathbf{d}$ formed, with the secondary aniline (7e) isolated in $79 \%$ yield. The reaction conditions also tolerated changes in the substituents in the D-ring of the heteroaryl bromide $(\mathbf{9 e}-\mathbf{j}) \cdot{ }^{37}$ The $[3+2]$ heteroannulation strategy was also compatible with the formation of carbazole-1,4-quinones (21a-f). ${ }^{26,38}$ Access to $N$-arylated products is also possible, forming a mixture of fused imidazoles (9k-1) via an $\mathrm{N}$-arylation step, alongside tertiary anilines (22-23).

The modularity of this strategy is also exemplified by the preparation of natural products Glycozoline $(\mathbf{9 m}),{ }^{39}$ Harmane $(9 \mathbf{n})^{40}$ and Murrayafoline A (9o). ${ }^{41-42}$ In addition, preparation of $9 \mathbf{p}$ demonstrates that the reaction conditions tolerate functional groups bearing potential Pd-chelating sites and bulky substituents ortho to the corresponding aryl bromide.

Our [3+2] heteroannulation strategy was extended to the targeted synthesis of biologically-active tetracyclic carbazoles. Carbazole-1,4-quinones (e.g., 21a-f) have established anti-cancer activity via topoisomerase inhibition or by the production of reactive oxygen species. ${ }^{38,43}$ We used $\mathbf{2 1} \mathbf{b}$ as a key intermediary scaffold for the targeted synthesis of a deaza analogue of the natural product 9-methoxyellipticine (Scheme 3b), producing 24 in 3 steps and in an overall yield of $20 \% \cdot{ }^{44}$ Further exemplification of our strategy was demonstrated by the preparation of alkylated $7 \mathrm{H}$-pyridocarbazoles (e.g. 9a-e) which have well-established anti-cancer activity. ${ }^{45-46}$ Previous preparative methods of this series of compounds have involved a 6-step linear synthesis affording compound $9 \mathrm{e}$ in $28 \%$ overall yield. ${ }^{45,47}$ Our two-step convergent strategy accessed the $7 \mathrm{H}$-pyrido[4,3-c]carbazole core $9 \mathbf{e}$ in a single step (83\%), followed by alkylation to produce mono- $N$-alkylated examples (25-26), and the potent anti-cancer agent ditercalinium (27). ${ }^{48}$

In summary, we have established a mechanistic framework for the preparation of fused tetracyclic carbazoles. We envisage that this convergent approach could find application in medicinal chemistry for structure-activity profiling and in broader synthetic applications which require step-efficient access to carbazole scaffolds.

\section{ASSOCIATED CONTENT}

\section{Supporting Information}

Preparation and characterization of small molecules and crystal structural information. The Supporting Information is available free of charge on the ACS Publications website.

\section{AUTHOR INFORMATION}

\section{Corresponding Author}

*Email: glenn.burley@strath.ac.uk 
(a) Substrate scope

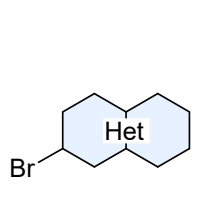

$\mathrm{Pd}(\mathrm{OAc}) 2$ (5 mol\%)<smiles>Cc1ccc(N)c(Cl)c1</smiles>
Het ligand $(10 \mathrm{~mol} \%)$ K3PO4 (3 equiv)

(i) $30 \mathrm{~min}, 120^{\circ} \mathrm{C} \mathrm{MW}$ (ii) $8 \mathrm{~h}, 160^{\circ} \mathrm{C} \mathrm{MW}$

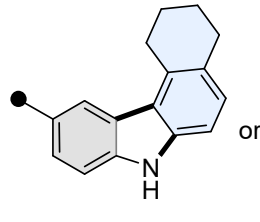

9a-j<smiles>O=C1c2ccccc2C(=O)c2c1[nH]c1ccc(O)cc21</smiles>

$1 a-d$

6a-f

tetracyclic systems<smiles>COc1ccc2[nH]c3ccc4ncccc4c3c2c1</smiles>

9g $65 \%$

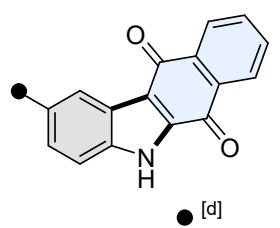

9e $83 \%$

9f $75 \%$<smiles>Cc1ccc2[nH]c3ccc4c(c3c2c1)COC4</smiles>

21a H $73 \%$

21b OMe $79 \%$

21c $\mathrm{Me} \quad 59 \%$

9c $\mathrm{CF}_{3} \quad 25 \%$

9i $94 \%$

9j $10 \%$

21d $\quad \mathrm{CF}_{3} \quad 35 \%$

9d $\mathrm{NO}_{2} \quad$ trace $^{[\mathrm{b}]}$

9h $90 \%$

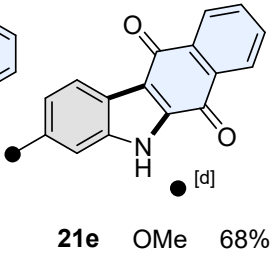

9k $25 \%$

$2252 \%$

$21 f \quad F \quad 58 \%$<smiles>COc1ccc2[nH]c3ccc(C)cc3c2c1</smiles>

Glycozoline

9m $36 \%(64 \%)^{[a]}$

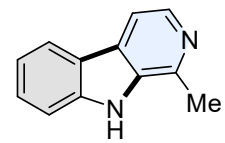

Harmane

9n $45 \%(40 \%)^{[a]}$ tricyclic carbazoles

9l $14 \%$

$2362 \%$

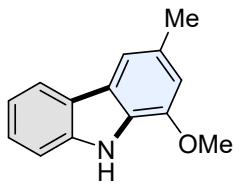

Murrayafoline A

9o $43 \%$ [a]

(b) Synthetic utility of carbazole 1,4-quinones

(c) Synthesis of alkylated $7 H$-pyridocarbazoles<smiles>COc1ccc2[nH]c3c(C)c4ccccc4c(C)c3c2c1</smiles>

24

$20 \%$ from 21b (3 steps) 6-deaza-9-methoxyellipticine<smiles>COc1ccc2[nH]c3ccc4c(c3c2c1)C=[N+](C)CC4</smiles>
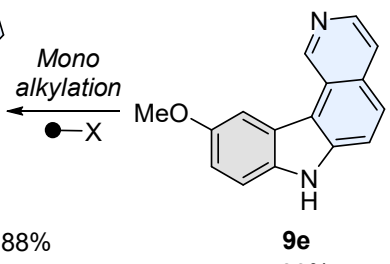

$83 \%$

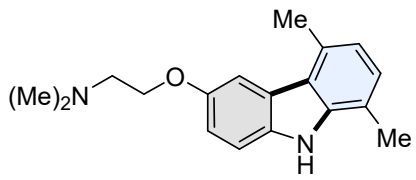

9p $22 \%[c]$

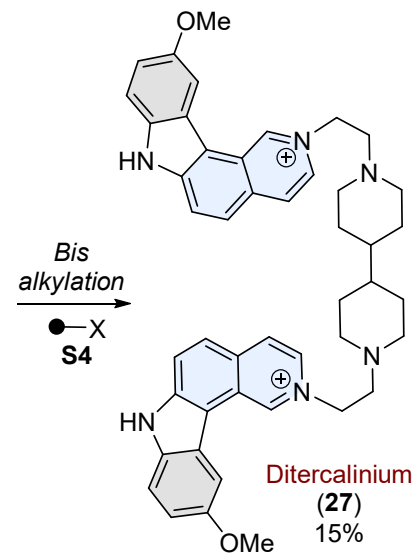

Scheme 3. (a) Scope and isolated yields of the [3+2]heteroannulation. ${ }^{[a]}$ Addition of $\mathrm{PivOH}(30 \mathrm{~mol} \%)$. ${ }^{[\mathrm{b}]}$ Formation of $7 \mathrm{e}$ in $79 \% .{ }^{[c]}$ Ligand $=\mathrm{HPtBu}_{3} \mathrm{BF}_{4} .{ }^{[\mathrm{d}]}$ Ligand = DavePhos. (b) Synthesis of 6-deaza-9-methoxyellipticine from 21b (Scheme S1).

(c) Synthesis of alkylated $7 \mathrm{H}$-pyridocarbazoles (Scheme S2).

Author Contributions

Conceptualization: G.A.B., E.C., A.T.S. O.I.P.; Methodology: E.C., O.I.P., A.T.S, J.B.; Validation: E.C., A.T.S.; Formal analysis: E.C., A.T.S.; Manuscript preparation: E.C., A.T.S., G.A.B. *These authors contributed equally.

\section{ACKNOWLEDGMENTS}

E.C. thanks the University of Strathclyde for a PhD studentship. O.I.P. thanks GSK and the Engineering and Physical Sciences Research Council (EPSRC) for an industrial CASE studentship. A.T.S. and G.A.B. thank the Biotechnology and Biological Research Council for funding (BB/R006857/1). 


\section{REFERENCES}

1. L.-S. Cui, H. Nomura, Y. Geng, J. U. Kim, H. Nakanotani and C. Adachi, Angew. Chemie Int. Ed., 2017, 56, 1571-1575.

2. A. W. Schmidt, K. R. Reddy and H.-J. Knölker, Chem. Rev., 2012, 112, 3193-3328.

3. A. Caruso, J. Ceramella, D. Iacopetta, C. Saturnino, M. V. Mauro, R. Bruno, S. Aquaro and M. S. Sinicropi, Molecules, 2019, 24, 1912.

4. C. M. Miller and F. O. McCarthy, RSC Adv., 2012, 2, 8883-

8918.

5. W. J. Andrews, T. Panova, C. Normand, O. Gadal, I. G. Tikhonova and K. I. Panov, J. Biol. Chem., 2013, 288, 4567-4582.

6. E. Tian, T. H. Landowski, O. W. Stephens, S. Yaccoby, B. Barlogie and J. D. Shaughnessy, Mol. Cancer Ther., 2008, 7, 500-509.

7. R. Fellous, D. Coulaud, I. El Abed, B. P. Roques, J.-B. Le Pecq, E. Delain and A. Gouyette, Cancer Res., 1988, 48, 6542-6549.

8. E. Conchon, F. Anizon, B. Aboab and M. Prudhomme, J. Med. Chem., 2007, 50, 4669-4680.

9. S. Issa, A. Prandina, N. Bedel, P. Rongved, S. Yous, M. Le Borgne and Z. Bouaziz, J. Enzyme Inhib. Med. Chem., 2019, 34, 13211346 .

10. S. N. Georgiades and P. G. Nicolaou, in Adv. Heterocycl. Chem., Eds. E. F. V. Scriven and C. A. Ramsden, Academic Press, 2019, vol. 129, pp. 1-88.

11. P. Ruiz-Castillo and S. L. Buchwald, Chem. Rev., 2016, 116, 12564-12649.

12. S. I. Gorelsky, D. Lapointe and K. Fagnou, J. Org. Chem., 2012, 77, 658-668.

13. M. Lafrance and K. Fagnou, J. Am. Chem. Soc., 2006, 128, 16496-16497.

14. M. Moir, J. J. Danon, T. A. Reekie and M. Kassiou, Expert Opin. Drug Discov., 2019, 14, 1137-1149.

15. B. Hong, T. Luo and X. Lei, ACS Cent. Sci., 2020, 6, 622-635.

16. R. B. Bedford, M. Betham, J. P. H. Charmant and A. L. Weeks, Tetrahedron, 2008, 64, 6038-6050.

17. R. B. Bedford and M. Betham, J. Org. Chem., 2006, 71, 9403-9410.

18. L. Ackermann, A. Althammer and P. Mayer, Synthesis, 2009, 2009, 3493-3503.

19. W. C. P. Tsang, R. H. Munday, G. Brasche, N. Zheng and S. L. Buchwald, J. Org. Chem., 2008, 73, 7603-7610.

20. T. Watanabe, S. Oishi, N. Fujii and H. Ohno, J. Org. Chem., 2009, 74, 4720-4726.

21. T. Watanabe, S. Ueda, S. Inuki, S. Oishi, N. Fujii and H. Ohno, Chem. Commun., 2007, 43, 4516-4518.

22. C. Börger, O. Kataeva and H.-J. Knölker, Org. Biomol. Chem., 2012, 10, 7269-7273.

23. S. Hostyn, G. Van Baelen, G. L. F. Lemière and B. U. W. Maes, Adv. Synth. Catal., 2008, 350, 2653-2660.

24. J. K. Laha, P. Petrou and G. D. Cuny, J. Org. Chem., 2009, 74, 3152-3155.
25. M. Wienhold, J. J. Molloy, C. G. Daniliuc and R. Gilmour, Angew. Chem. Int. Ed., 2021, 60, 685-689.

26. N. Ramkumar and R. Nagarajan, J. Org. Chem., 2014, 79, 736-741.

27. P. Chen, D. Norris, K. D. Haslow, T. G. Murali Dhar, W. J. Pitts, S. H. Watterson, D. L. Cheney, D. A. Bassolino, C. A. Fleener, K. A. Rouleau, D. L. Hollenbaugh, R. M. Townsend, J. C. Barrish and E. J. Iwanowicz, Bioorg. Med. Chem. Lett., 2003, 13, 1345-1348.

28. D. Kim, G. Choi, W. Kim, D. Kim, Y. K. Kang and S. H. Hong, Chem. Sci., 2021, 12, 363-373.

29. L. C. Campeau, M. Parisien, A. Jean and K. Fagnou, J. Am. Chem. Soc., 2006, 128, 581-590.

30. L. C. Campeau, P. Thansandote and K. Fagnou, Org. Lett., 2005, 7, 1857-1860.

31. D. Alberico, M. E. Scott and M. Lautens, Chem. Rev., 2007, $107,174-238$

32. T. Iwaki, A. Yasuhara and T. Sakamoto, J. Chem. Soc., Perkin Trans. 1, 1999, 11, 1505-1510.

33. J. A. Jordan-Hore, C. C. C. Johansson, M. Gulias, E. M. Beck and M. J. Gaunt, J. Am. Chem. Soc., 2008, 130, 16184-16186.

34. J. D. Winkler, B. M. Twenter and T. Gendrineau, Heterocycles, 2012, 84, 1345-1353.

35. C. Sambiagio, D. Schönbauer, R. Blieck, T. Dao-Huy, G Pototschnig, P. Schaaf, T. Wiesinger, M. F. Zia, J. Wencel-Delord, T. Besset, B. U. W. Maes and M. Schnürch, Chem. Soc. Rev., 2018, 47, 6603-6743.

36. Z. Yang, F.-C. Qiu, J. Gao, Z.-W. Li and B.-T. Guan, Org. Lett., 2015, 17, 4316-4319.

37. L.-C. Campeau, M. Parisien, A. Jean and K. Fagnou, J. Am. Chem. Soc., 2006, 128, 581-590.

38. N. Suematsu, M. Ninomiya, H. Sugiyama, T. Udagawa, K. Tanaka and M. Koketsu, Bioorg. Med. Chem. Lett., 2019, 29, 22432247.

39. Q. Yan, E. Gin, M. Wasinska-Kalwa, M. G. Banwell and P. D. Carr, J. Org. Chem., 2017, 82, 4148-4159.

40. S. Ding, Z. Shi and N. Jiao, Org. Lett., 2010, 12, 1540-1543.

41. V. Humne, Y. Dangat, K. Vanka and P. Lokhande, Org. Biomol. Chem., 2014, 12, 4832-4836.

42. T. Szabó, B. Volk and M. Milen, Molecules, 2021, 26, 663.

43. C. Zhang, S. Li, L. Ji, S. Liu, Z. Li, S. Li and X. Meng, Bioorg. Med. Chem. Lett., 2015, 25, 4693-4696.

44. A. T. Boogaard, U. K. Pandit and G.-J. Koomen, Tetrahedron, 1994, 50, 4811-4828.

45. D. Pelaprat, R. Oberlin, I. L. Guen, J. B. Le Pecq and B. P. Roques, J. Med. Chem., 1980, 23, 1330-1335.

46. P. Leon, C. Garbay-Jaureguiberry, M. C. Barsi, J. B. Le Pecq and B. P. Roques, J. Med. Chem., 1987, 30, 2074-2080.

47. P. Leon, C. Garbay-Jaureguiberry, B. Lambert, J. B. Le Pecq and B. P. Roques, J. Med. Chem., 1988, 31, 1021-1026. 